\title{
PUNISHMENT IN A LINEAR PUBLIC GOOD GAME WITH PRODUCTIVITY HETEROGENEITY
}

\author{
FANGFANG TAN*
}

Summary

\begin{abstract}
Although it is widely recognized that sanction increases cooperation in a public good game, comparatively little attention has been paid to a scenario in which agents have heterogeneous productivities (i.e. asymmetric impact on the group account). This paper examines the extent to which sanction works in this scenario by varying marginal per capita return (MPCR) among group members. Experimental results indicate that in the absence of sanctions, productivity heterogeneity hampers cooperation. Allowing punishment in these groups significantly enhances average contributions of group members, but does not increase welfare. In groups in which cooperation is highly successful, high-productivity agents actively punish low-productivity agents in initial periods. However, conditional on individual contributions, high-productivity agents receive more punishment, and behave more responsively by raising their contributions in the next period. The results mirror the reality in which elites in a society are under higher pressure, since their choices are likely to have a deeper impact on a society.
\end{abstract}

Key words: linear public good, heterogeneity, MPCR, productivity, punishment, VCM

\section{INTRODUCTION}

The ever-increasing expansion of knowledge in day-to-day life has resulted in greater demand for cooperation, and teamwork is increasingly being perceived as a crucial part of being successful. When some members of a group driven by self-interest withhold their effort contributions, the enforcement of sanctions is a common means through which people retaliate against perceived injustices. Examples of sanctions include fines and restrictions that may be implemented by a legal system, or costs of money and time that may be imposed by private individuals on the offender (Masclet et al. (2003)).

Sanction behavior has been investigated extensively via a laboratory experiment called voluntary contribution mechanism (VCM), or public good game (PGG). In this game, every member of the group receives an initial endowment of money, and members have to choose simultaneously the proportion

* Department of Economics, Tilburg University, P.O. Box 90153, 5000 LE Tilburg,

The Netherlands, e-mail: F.Tan@uvt.nl. 
of money they keep for themselves and the proportion of money to be placed in a public account that would be of benefit to everyone. Each member, after observing the individual contribution of all the others, has an opportunity to reduce the earnings of any group member at his or her own cost. Given the parameters set in VCM, the dominant strategy for a participant is to have zero contribution and to never punish. Nevertheless, most public good games with punishment observe a prevalent use of sanctions. These credible punishment threats sustain cooperation effectively (Yamagishi (1986); Ostrom et al. (1992); Fehr and Gächter (2000, 2002); Masclet et al. (2003)).

So far, the punishment literature on VCM has focused mainly on symmetric players having the same impact on the group account in the contribution stage. In most real-world scenarios, however, symmetric players are the exception rather than the norm, while the asymmetry across different group members is a feature of many situations of interest. A common example that comes to mind involves a group of students working together on a project. For some students, less effort is needed to achieve the same progress than is the case for others, due to their relatively higher abilities or richer experience. Similarly, larger firms in a cartel of a certain industry are more likely to have stronger bargaining power in negotiations with the government because of their size and capacity in market share. In this paper, a situation in which different group members have asymmetric impacts on a collective goal is referred to as "productivity heterogeneity". The aim of this study is therefore to investigate the efficiency of the sanction system under productivity heterogeneity: if individual members of a group of agents with asymmetric productivities are allowed to express disapproval against the actions of each other, then who determines the punishment and who gets punished? Do behavioral differences occur when various members react to punishment? To the best of my knowledge, this is the first study on this topic.

A starting point for the analysis will be the selection of an appropriate proxy for productivity. A key parameter in the public good game, marginal per capita return (MPCR), is the benefit that each participant receives from each money unit contributed to the group account by any group member. Since a higher MPCR reduces the cost of contributing to the group account and consequently may induce an increase in contributions, it may be considered as a proxy for the productivity of group subjects (Isaac and Walker (1988)). Hence, the higher the productivity of a subject (which is equivalent with the case of a higher MPCR), the less effort it takes that subject to contribute a given amount of output. Hereafter, the term MPCR will be used interchangeably with productivity.

To implement this experiment, the study observes cooperation and punishment behavior in a treatment with heterogeneous agents (where agents have different MPCRs to the public account) and compares the results to the existing literature. Since little analysis has been carried out to explore 
the effect of productivity heterogeneity, I will attempt to fill the gap by also analyzing a treatment with heterogeneous agents but with no sanction opportunities. ${ }^{1}$ The effect of productivity heterogeneity can therefore be measured by comparing this treatment with a symmetric one (in which all agents have the same MPCR), controlling for average productivity.

The remainder of the paper proceeds as follows. Section 2 presents public good game experiments related to heterogeneity and sanctioning. Section 3 derives hypotheses according to the existing literature. Section 4 describes the experiment implementation, and Section 5 illustrates the results. Section 6 provides concluding remarks.

\section{LITERATURE REVIEW}

Many studies have uniformly found that players in VCM games exhibit a substantially higher rate of cooperation than can be expected under the assumption of the standard economic model of the self-interested actor. Contribution rates of $40-60 \%$ are reported by many studies, but they decrease with repetition (Kim and Walker (1984); Isaac et al. (1985); Andreoni (1988); Isaac and Walker (1988); Weimann (1994)).

\subsection{Literature on Heterogeneity}

There are several ways to generate asymmetry in VCM. The first way is to allow variation of MPCR. Many public good studies have found that a higher MPCR reduces the contribution cost, which implies a higher chance of contribution. Ledyard (1995), surveying the literature on public good games, concludes that MPCR has a strong positive effect on contribution rates.

To the best of my knowledge, most of the experiments addressing productivity variation are not linear public good games (Marwell and Ames (1979, 1980); Bagnoli and Mckee (1991)). Fisher et al. (1995) is the only study that examines exclusively the effect of asymmetric MPCR structure based on a linear public good game. In their experiment, subjects are separated into groups of four - two with a high MPCR (0.75) and two with a low MPCR (0.3). A total of twenty periods are divided into two stages, and the MPCRs of all subjects are shifted from one to the other after the tenth period. They conclude that the subjects seem to focus only on their own MPCR, for whoever is assigned MPCR 0.75 contributed more than the one who is assigned MPCR 0.3. This reduces the group average contributions in an asymmetric group to an intermediate level between baseline groups featuring a high- and low-MPCR. Their experiment differs from ours in two respects. First, their 
comparisons are based on the average contribution level of a mixed group and that level is the weighted average of two homogeneous groups with extreme MPCRs. This study, in contrast, is based on a mixed group and a homogeneous group with the same average MPCR. The second difference is that the information structures vary in two settings. In Fisher et al. (1995), participants are not told explicitly that different individuals necessarily have different MPCRs, but simply that the MPCRs are not necessarily the same. The MPCR information is also private when the experimenters inform the subjects about the MPCR changes. This experiment, however, makes productivity distributions explicit among all players so as to allow richer reciprocal interactions. Ledyard (1995) gives a tentative conjecture that productivity heterogeneity lowers the rate of contribution, unless there is incomplete information and no repetition. ${ }^{2}$

Apart from the asymmetric payoff structure, another way to generate heterogeneity is by varying the endowments of the players. Unlike the studies on productivity, the results of these studies on endowment heterogeneity are contradictory and non-conclusive. A number of studies report that asymmetric endowments decrease the cooperation level, especially when all players know the asymmetry (Anderson et al. (2004); Cherry et al. (2005); Oxoby and Spraggon (2006)). Nonetheless, several other studies find that endowment asymmetry does not so much hamper as promote contribution (Chan et al. (1996); Buckley and Croson (2006)).

In addition to the studies focusing exclusively on productivities and endowments, heterogeneity can also be generated by other means. Some studies interact both forms of heterogeneity under different information structures (Chan et al. (1999)), some generate asymmetries in the dynamics of the game by introducing leaders (Potters et al. (2007)), and a few other experiments do the same by varying private account valuations across agents (Palfrey and Prisbrey (1997)). Due to different game settings, the results differ significantly and cannot be compared directly with each other.

\subsection{Literature on Sanctions}

Sanction is considered to be one of the most robust mechanisms for eliciting contributions. The earliest studies on sanctioning systems under VCM are carried by social psychologists (Yamagishi (1986)) and political scientists (Ostrom et al. (1992)). They find that this mechanism can be self-maintained, and that it serves to increase contribution levels.

2 Ledyard also points out that the effect of heterogeneity on cooperation is quite weak: "there does not yet appear to be enough evidence for acceptance. Quite often there is conflicting evidence." 
An influential economic experiment conducted by Fehr and Gächter (2000) (hereafter FG), devises a situation in which the possibility of strategic punishment can be removed. In the first stage of the experiment, four subjects play a standard public good game. In the second stage, each subject, after reading the contributions and earnings of the all group members, is given a chance to reduce the earnings of any other player or players in his or her group by using his or her earnings in the contribution stage. Game theory predicts that the unique sub-game perfect equilibrium to this finite two-stage game is that agents never punish in the second stage because any punishment will be costly for them. Since the threat of punishment is not credible, no one will contribute to the group account in the first stage. However, FG observe a significant positive amount of punishment mete out by subjects, and free riding is remarkably curtailed accordingly. This result is obtained under both Partner Treatment (the four subjects remain in the same group for all ten periods) and Stranger Treatment (the subjects are randomly reassigned after each round). Many subsequent studies replicate the experiment and obtain similar results (Bowles et al. (2001); Fehr and Gächter (2002); Masclet et al. (2003); Noussair and Tucker (2005); Sefton et al. (2007)).

There have been many extensions of FG on varying parameters of a VCM game. For instance, Bowles et al. (2001) extends FG's experiment to measure the sanctioning effect under different group sizes and MPCRs to the public account. Their data suggest that the amount of punishment received by free riders is increasing in both group size and MPCR. As a result, the contribution levels of large groups with a high MPCR are very high when punishment is allowed. As an extension of Bowles et al. (2001), Carpenter (2007) systematically examines the interaction of group size, MPCR and monitoring technology. He reports that punishments are sensitive to group structures. Sefton et al. (2007) extends FG's experiment by adding a Reward Treatment (where players can give a bonus to others based on contributions) and a Combined Treatment (where players can both award and punish each other), and shows that the Combined Treatment works most effectively in promoting contributions. Asymmetric sanctioning power is investigated recently. Nikiforakis et al. (2007) discovers that asymmetries in the distribution of punishing abilities seem to have no effect on either the level or the evolution of cooperation over time. What increases cooperation levels is the higher average ability to punish.

Sanction motivation is another interesting issue. Researchers have discovered that punishments are not merely monetary based; the expression of disapproval itself is also found to be effective. Masclet et al. (2003) and Noussair and Tucker (2005) provide evidence of cooperation being enhanced purely by "cheap talk"; that is, the opportunity for agents to express disapproval of other's decisions without deducting their monetary earnings. Likewise, Carpenter et al. (2004) conducts a field experiment by imposing cost to punishers but keeping at zero the mate- 
rial harm to those who were punished. This study discovers that the sanction mechanism enhances cooperation in only one of the two samples.

While punishment tends to increase cooperation, it is not a panacea: if individuals are given the possibility to counter-punish, then cooperation quickly breaks down (Denant-Boemont et al. (2007); Nikiforakis (2008)). In addition, Bochet et al. (2006) reports that punishment, while discouraging free riding, does not raise contribution as efficiently as communication does. Note that all of the above-mentioned studies on punishment assume that players have symmetric impacts on the group account in the contribution stage.

\section{PRELIMINARY CONJECTURES}

The literature mentioned in Section 2 cannot provide any comparable results on a heterogeneous and homogeneous group with the same average MPCR for this experiment. The only reliable clue available to us is a pattern in Fisher et al. (1995) that shows that the average group contribution of asymmetric groups is always between those of the high- and low-MPCR baseline groups. Since MPCR links positively with contribution, the contributions of two groups with the same average productivity can reasonably be expected to be similar.

Hypothesis 1 (Heterogeneous Productivity Hypothesis): Without sanctioning, the group average contribution of a heterogeneous group is the same as that of a homogeneous group with the same average MPCR.

Behavioral differences between the types are found in most of the abovementioned studies. High MPCR are usually associated with higher contribution levels, and vice versa. For example, the discussion in Marwell and Ames (1979) reports that the "low interest" subjects are expected to undercontribute to the public good. Isaac et al. (1985) observes that individuals in high payoff conditions contribute more than individuals in low payoff conditions. Similarly, Fisher et al. (1995) find that high MPCR types, on average, contribute more than low-MPCR types do, in every period. I therefore propose the following hypothesis:

Hypothesis 2 (Productivity Determinant Hypothesis): In the absence of sanction opportunities, individual contribution increases when a player faces a higher $M P C R$.

To the best of my knowledge, no previous study has explored punishment under productivity heterogeneity. Although several variants of sanction mechanisms could be used, this paper, as a tentative exploration, replicates only the canonical form of the punishment mechanism in FG's experiment. Based on the robust findings in previous experiments, punishment institution is anticipated as also being effective in terms of fostering cooperation in a heterogeneous game. 
Hypothesis 3 (Monetary Punishment Hypothesis): In the presence of heterogeneity, the opportunity for agents to reduce the monetary payoff of others after observing their decisions will increase group average contribution levels.

If the punishment institution were effective, who would become the enforcers in shaping the cooperation of the players? Olson (1971) proposes that a "dominant power" will have a positive effect on cooperation. This means that players with stronger incentives or power to provide the social goods will punish more. According to Fehr and Gächter (2002), 74.2\% of these punishments are executed by above-average contributors to belowaverage contributors. Combining what Hypothesis 2 (that contribution rises when a player has a higher MPCR), we can see that low-MPCR players are expected to be the free riders while high-MPCR players are expected to be the "dominant power", or cooperation enforcers in the group.

Hypothesis 4 (Punishment Enforcement Hypothesis): Given sanction opportunities, punishments are imposed by high-MPCR subjects to low-MPCR subjects.

However, the situation at each given individual contribution level will be different. Bowles et al. (2001) analyzes the way in which punishment affects individual contributions, and finds that the punishment a player receives from other group members increases saliently when the MPCR of the group account rises. Even though all players in this game are symmetric in productivity, similar results can be expected in this study. The logic behind this is natural: It is cheaper to spur on members to make additional contributions when their impact on the group account return increases, since every single contribution will give rise to more positive externalities to all group members. Therefore, Hypothesis 5 is given as follows:

Hypothesis 5 (Conditional Punishment Hypothesis): Conditional on individual contribution, high MPCR subjects receive more punishment.

The experiment is designed to test cooperation and sanction behavior under productivity heterogeneity in a four-person linear public good game. The treatment variables are MPCR and the introduction of a sanction mechanism. The baseline treatment, Treatment 1 (T1), replicates the standard VCM with a homogeneous MPCR 0.6 of all group members. Treatment 2 (T2) is identical to T1, except for one difference. Instead of all subjects being endowed with the same MPCR, half of the group members have a high MPCR of 0.9, and the other half have a low MPCR of 0.3. T2 is used as a control group for Treatment 3 (T3). In T3, a sanction mechanism is added on top of T2. T3 is the key treatment for studying the effect that punishment brings to the cooperation level in a heterogeneous group, controlling for the average productivity. 


\section{THE EXPERIMENT}

The experiment consisted of nine sessions conducted at CentER Lab, at Tilburg University. Each treatment, T1, T2 and T3, was in effect in three of the sessions. Seventy-two subjects, among whom 50\% were females, were recruited via email contact from an experiment candidate list provided by CentER Lab. Subjects who majored in graduate level Economics were excluded. Some of the subjects had previously participated in economic experiments, but all were inexperienced with the voluntary contributions mechanism. Each subject participated in only one session of the study. Since the student population in the contact list was rather large (about 1,400), the subjects were unlikely to know each other. The experiment was programmed and conducted with the software z-Tree Fischbacher (2007), developed at the Institute for Empirical Research in Economics at the University of Zurich.

Each session included eight participants that were separated into two groups of four. Before the start of each session, the computer program randomly designated the subjects into different groups according to their choices of terminal upon entering the room for the session. All three treatments adapted Partner Matching protocol, under which group assignments remained constant throughout the experiment. ${ }^{3}$ A session consisted of 15 rounds. All 15 rounds of play counted towards final earnings, and there were no practice periods at the beginning of the sessions. At the beginning of each period every player was randomly given a number between 1 and 4 to distinguish their actions from those of the others during that period. To prevent the formation of individual reputation, the numbers were randomly reallocated at the beginning of every period. ${ }^{4}$ In addition, participants in T2 and T3 were also informed of their productivity levels at the beginning of the experiment. These roles remained fixed for the duration of the experiment. ${ }^{5}$ The above settings were common knowledge to all participants.

The instructions used in the experiment were modified on the basis of those used in Noussair and Tucker (2005). During each round, every subject was endowed with 10 tokens, with a conversion rate of 25 tokens $=1$ Euro. Subjects simultaneously chose the number of tokens to keep for themselves

3 The purpose of choosing partner-matching protocol in this study is to simulate reality in which the members of a project team or a union working towards a common goal do not vary within a certain time period.

4 Such a mechanism ensures that, even though the group members remain the same, the participants cannot link the actions of the other subjects across the periods. Thus, retaliation as in Denant-Boemont etal. (2007) and Nikiforakis (2008) is not possible.

5 I used neutral language in the experiment. Players with MPCR 0.9 were "type A" and players with MPCR 0.3 were "type B". Moreover, sensitive terminologies such as "contribution" and "punishment" were avoided so as not to create biased decisions. For example, punishment was termed as "points that reduce another player's income". 
and those to put in the public account. T3 added a punishment stage after the contribution decision in which subjects decided whether or not to register disapproval of each group member's decision by sending points to them. The entire experiment was done by subjects anonymously interacting with each other without informing them about the identity of the other group members, and communication was strictly forbidden all of the time.

\subsection{Treatment 1 (T1)}

In the baseline treatment T1, the MPCR of all group members was 0.6, which meant that each token put into the group account yielded a payoff of 0.6 token to every member in the group. The rest of the tokens that were kept by the subjects went to their private accounts. Therefore, the income in each round was calculated as

$$
I_{i}=10-C_{i}+0.6 \times \sum_{k=1}^{4} C_{k}
$$

where $C_{i}$ was the contribution of agent $i$, and $\sum_{k=1}^{4} C_{k}$ was the sum of contributions to the group account by all the members in the group, including agent $i$. After they finished making decisions, the subjects were shown the contribution and earnings of every group member for every time period.

\subsection{Treatment 2 (T2)}

Heterogeneous productivity was generated in T2 by randomly assigning half of the group members a high MPCR of 0.9 and the other half a low MPCR of 0.3. The two MPCR levels were chosen such that the average MPCR of four group members equaled to 0.6 , which was comparable with T1. The income calculation from the private account remained unchanged from T1, but the income from the group account was calculated as $90 \%$ of the total input of group members with MPCR 0.9 to the project plus $30 \%$ of the total input of group members with MPCR 0.3 to the project. That is, the income in each round in $\mathrm{T} 2$ should be

$$
I_{i}=10-C_{i}+0.9 \times \sum_{h=1}^{2} C_{h}+0.3 \times \sum_{l=1}^{2} C_{l}
$$

where $C_{i}$ was the contribution of agent $i$ (no matter what MPCR he or she has), and the third and fourth items were the sum of contributions of two high- and low-MPCR subjects to the group account respectively (agent 
$i$ included). Since the income calculation was more complicated than in T1, this calculation was posted together with the contributions and earnings of the agent's peers for each round. Note that even though this income calculation was different from the homogeneous case, both games had the same unique sub-game perfect Nash Equilibrium of zero contribution for all players, if the games were repeated finitely.

\subsection{Treatment 3 (T3)}

T3 was divided into two stages. The first stage was a replication of T2. After contribution decisions were made, the sanction mechanism was added in the second stage. At the beginning of the second stage, the experimenter informed all subjects of the amount that each of the other three members of their group contributed. Subjects were then given the opportunity to send points ranging from 0 to 10 to every group member. The random ID assignment setting mentioned above made it difficult to for an agent to track the contribution decision of another agent from one period to the next, or to target him or her specifically for punishment beyond the current period. Every point that a particular subject sent to another reduced his or her earnings by one token and reduced the earnings of the recipient by two tokens. Agent $i$ 's earnings in $\mathrm{T} 3$ thus became

$$
I_{i}=10-C_{i}+0.9 \times \sum_{h=1}^{2} C_{h}+0.3 \times \sum_{l=1}^{2} C_{l}-\sum_{k \neq i} P_{i k}-2 \times \sum_{k \neq i} P_{k i}
$$

where $\sum_{k \neq i} P_{i k}$ was the sum of points agent $i$ sent to all group members, and $\sum_{k \neq i} P_{k i}$ was the sum of points agent $i$ received from all other subjects. Again, the sub-game perfect equilibrium of this finite repeated game was that nobody punishes and thus nobody contributes.

At the end of the second stage, the computer displayed the agent's own type, the tokens he or she and all group members put into the project, the total number of points he or she received and assigned to others, the income of this round and its calculation. However, agents were neither informed about the punishment information of other members, nor did they know the individual punishment sent by a specific player.

On average, a session lasted 50 minutes (including initial instruction and payment of the subjects), and a subject earned an average of 215.55 tokens (approximately 8.62 Euros). Table 1 summarizes the structure of the experiment as a whole. 
TABLE 1 - SUMMARY OF TREATMENT DESIGNS

\begin{tabular}{llllll}
\hline $\begin{array}{l}\text { Treatment Section } \\
\text { names }\end{array}$ & $\begin{array}{l}\text { Subject } \\
\text { number }\end{array}$ & $\begin{array}{l}\text { Group } \\
\text { number }\end{array}$ & MPCR & $\begin{array}{l}\text { Punishment } \\
\text { allowed }\end{array}$ \\
\hline T1 & 3 & 24 & 6 & All equal to 0.6 & No \\
T2 & 3 & 24 & 6 & Half equal to 0.9; Half equal to 0.3 & No \\
T3 & 3 & 24 & 6 & Half equal to 0.9; Half equal to 0.3 & Yes \\
\hline
\end{tabular}

\section{RESULTS AND INTERPRETATION}

\subsection{Treatment Effects}

The focus of this section is group behavior. The principal research questions involve pairwise comparisons of contributions and earnings in three treatments in order to investigate how the sanction mechanism affects cooperation and punishment behavior under productivity heterogeneity.

Figures 1 and 2 display the total contribution levels for each of the six groups as a percentage of the total endowment in T1 and T2, respectively, over the 15 periods. The bold lines indicate the average contributions over all groups within a treatment. A glance at these lines reveals that both T1 and T2 show patterns similar to those reported in the current literature. The contribution rates are strictly positive at the initial stages (around $55 \%$ of endowment for $\mathrm{T} 1$ and $35 \%$ of endowment for $\mathrm{T} 2$ ), then fall consistently in later periods to the range between $10 \%$ and $20 \%$ of endowment in both treatments.

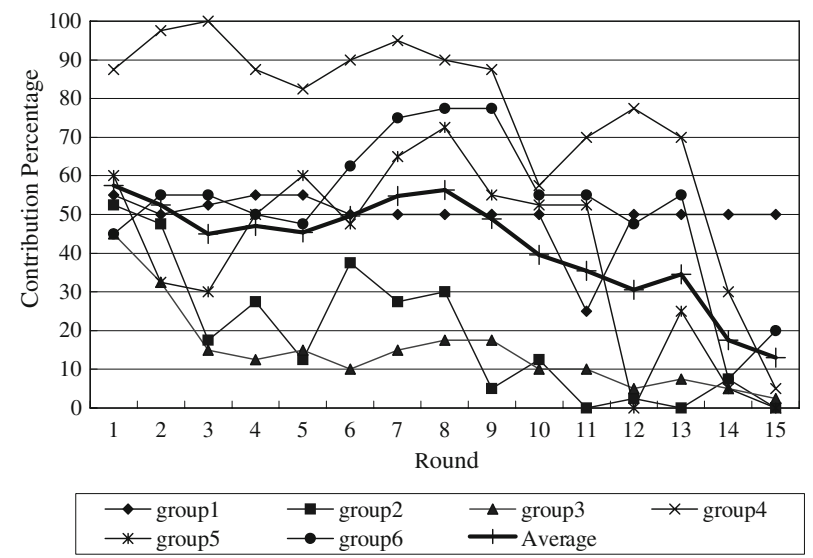

Figure 1 - Group contribution levels as a percentage of optimum (T1) 


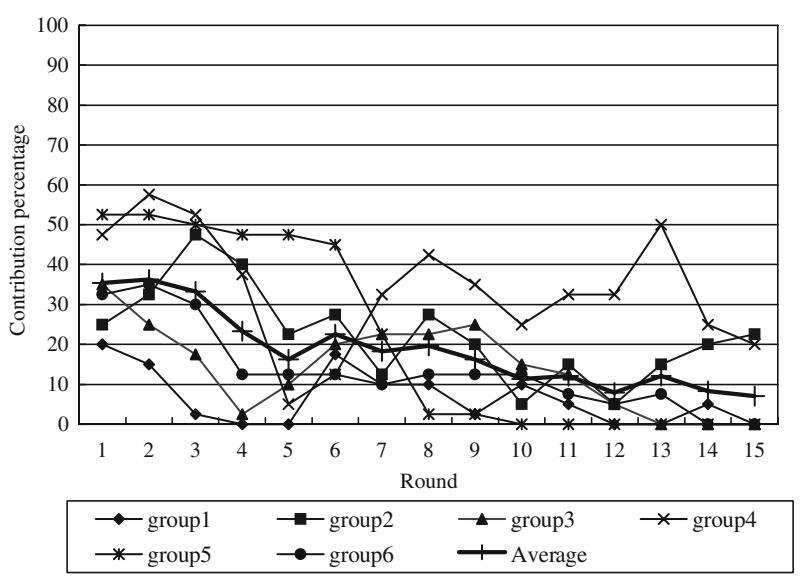

Figure 2 - Group contribution levels as a percentage of optimum (T2)

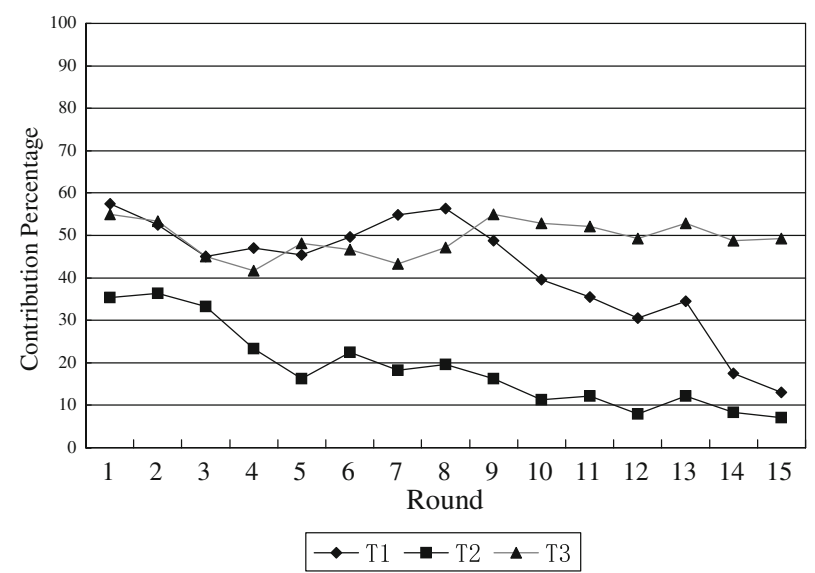

Figure 3 - Average group contribution levels by treatment

Figure 3 puts the average contribution lines by three treatments to the same graph. Note that the line in T2 lies consistently below that in T1 throughout the 15 time periods, indicating that the group average contribution rate in $\mathrm{T} 2$ is lower than that in $\mathrm{T} 1$.

RESULT 1 The heterogeneous Productivity Hypothesis (Hypothesis 1) is not supported. Without sanctions, the average contribution as a percent of optimum in a heterogeneous group (T2) is less than that of a homogeneous group (T1) with the same average MPCR. 


\section{SUPPORT FOR RESULT 1:}

Group average contribution is $41.8 \%$ for T1 and $18.67 \%$ for T2. A twosided Mann-Whitney rank-sum test of difference yields $\mathrm{z}=-1.922$ with $p<0.1$. Therefore, heterogeneity in productivity seems to reduce the group average contribution level when sanction is not possible.

The contribution rate in $\mathrm{T} 2$ is significantly lower than that in $\mathrm{T} 1$ because high-productivity subjects (MPCR 0.9) do not significantly increase their contributions, but low-productivity subjects (MPCR 0.3) free ride dramatically, compared to a median productivity group with MPCR 0.6. Figure 4 illustrates the mean contributions by period in each of the three MPCR types. Although they vary greatly in the early periods, they all converge to zero in the final periods. The patterns of high-MPCR types and low-MPCR types in this study are consistent with the finding in Fisher et al. (1995). In both studies, contributions of high-MPCR types dominate those of low-MPCR types for all time periods. However, as described in Result 2 below, it is not the case that subjects with higher MPCRs will contribute more.

RESULT 2 The Productivity Determinant Hypothesis (Hypothesis 2) is not supported in this study. In particular, the contribution of high-MPCR types is not significantly higher than that of the median-MPCR types in homogeneous groups. Moreover, contribution levels converge to zero for both highand low-MPCR types in the final periods.

\section{SUPPORT FOR RESULT 2:}

The average contribution level of the low-MPCR types of this study and those of Fisher etal. (1995) are similar in the sense that they both start around $25 \%$, and then decay towards zero over time. The mean contribution for the low-MPCR type is $11.78 \%$ of the endowment, which is significantly lower than the other two MPCR types (compared with median productive subjects, a Mann-Whitney rank sum test yields $\mathrm{z}=-2.082$ with $p<0.05$; while compared with highly productive subjects, $\mathrm{z}=-1.922$ with a $p<0.1$ ). However, high-MPCR types do not contribute as much as Hypothesis 2 leads us to expect if we compare the results of this experiment with those of Fisher et al. (1995). In their study, the average contribution of subjects with an MPCR of 0.75 is around $40 \%{ }^{6}$ If Hypothesis 2 holds, then the average contribution of subjects with an MPCR of 0.9 in this study should be higher. However, this figure turns out to be only $25.4 \%$. This number is also lower than that of a homogeneous group with the same average MPCR (41.81\%), but the difference is not significant at the $10 \%$ level $(\mathrm{z}=-1.441)$. As it is shown in Figure 4, the contribution levels of median-MPCR types in T1 and high-MPCR types in T2 are quite similar in the first three rounds. In later

6 Due to the lack of specific data, this number is estimated based on Figure 3 of Fisher et al. (1995). 
periods however, contribution level in $\mathrm{T} 2$ falls more dramatically than that of T1. Considering that information on productivity, contribution and earnings of all group members is made explicit at the end of each period, it would be natural to link the insufficient contributions observed in high-MPCR types with the severe free riding behavior among the low-MPCR types.

Results 1 and 2 allow us to conclude that when sanction is not possible, productivity heterogeneity decreases the group cooperation level. We now turn to the situation in which the sanction mechanism is present.

Figure 5 illustrates the group average contributions by period in T3. Two extreme cases can be detected from this figure. On one hand, three out of six groups have obvious rising trends in their mean contribution levels from approximately $60 \%$ in the first period to nearly $90 \%$ in the final period, implying a large extent of cooperation. On the other hand, the other three groups exhibit precisely the opposite behavior. Contribution levels descend from the same starting point of $60 \%$ in the first period to less than $10 \%$ in the final period, implying a cooperation failure. These two trends offset each other, causing the average contribution line in T3 to hover around $50 \%$ throughout the time of the study. ${ }^{7}$

RESULT 3 The monetary Punishment Hypothesis (Hypothesis 3) is supported. In the presence of productivity heterogeneity, average contribution levels are higher when sanctions are available. In particular, heterogeneous groups with punishment (T3) have mean contribution rates similar to those of the homogeneous groups without punishment (T1), controlling for the average MPCR.

\section{SUPPORT FOR RESULT 3:}

The mean contribution is $18.67 \%$ for T2 and $49.33 \%$ for T3. The MannWhitney rank-sum test of difference between T2 and T3 yields $\mathrm{z}=-2.082$, $p<0.05$. This means that the contribution level of $\mathrm{T} 3$ is higher than that of $\mathrm{T} 2$ at the $5 \%$ significance level. The test statistic comparing $\mathrm{T} 1$ with T3 suggests that the difference is not significant at any conventional level $(\mathrm{z}=-0.801)$.

As indicated in Figure 3, the average group contribution level of T3 lies significantly above $\mathrm{T} 2$, especially in periods $11-15(\mathrm{z}=-1.92$ with $p<0.05)$. Comparing $\mathrm{T} 3$ to $\mathrm{T} 1$, the two lines are entangled in the first nine periods; from the tenth period on, the average contribution level starts to decay steadily in T1, while it remains the same in T3, although the difference is not significant at the $10 \%$ level. Consistent with the current literature on punishment (such as Fehr and Gächter (2000)), this result reveals the power of

7 Since there are only six groups in T3, this result may not be robust. Nevertheless, as a tentative study, I treat this fact as given, and proceed to seek a plausible explanation. 


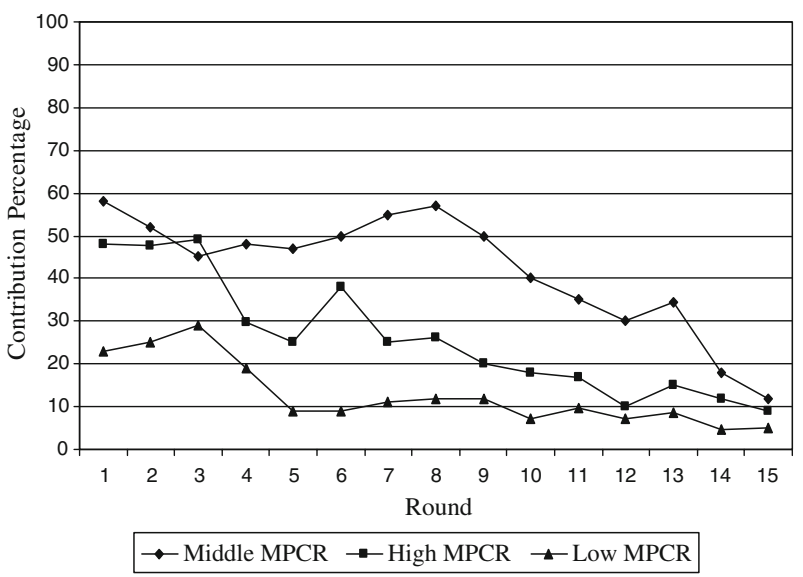

Figure 4 - Average contribution levels by MPCR types

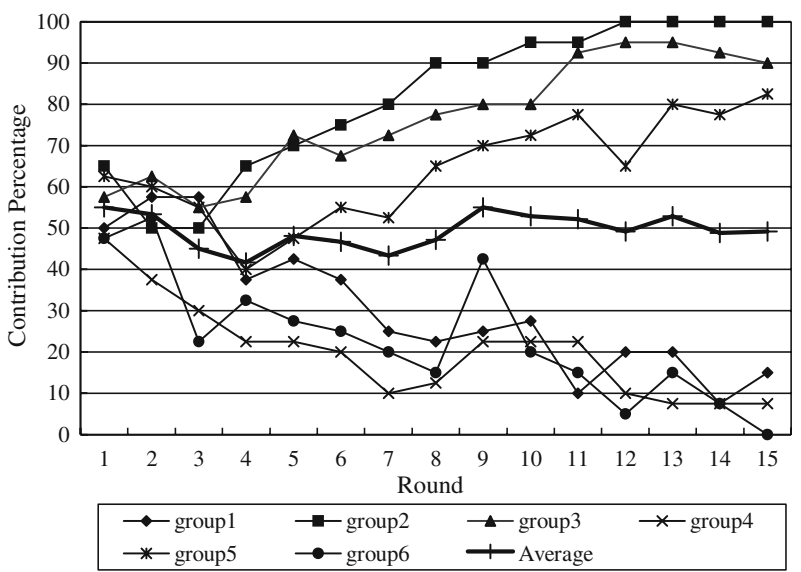

Figure 5 - Group contribution levels as a percentage of optimum (T3)

sanction in preventing the decay of cooperation towards the non-cooperative equilibrium level.

The mean contribution of the three groups with rising trends in Figure 5 is greater than that of the other three groups with declining trends (A MannWhitney rank sum test yields $\mathrm{z}=-1.964$ with $p<0.05$ ). What is behind such an extreme result - that three groups successfully cooperate while the other three fail? In order to answer this question, I find it helpful to probe sanction behavior by type. Result 4 summarizes the findings.

RESULT 4 The punishment Enforcement Hypothesis (Hypothesis 4) is supported in this study. Overall, more punishment points are assigned by 
high-MPCR types in successful groups than by those in failed groups. Moreover, low-MPCR types in successful groups receive more punishment than their counterparts in the failed groups. In sum, punishment is imposed by high- MPCR subjects on low-MPCR ones in successful groups.

\section{SUPPORT FOR RESULT 4:}

Using Figure 5, I designate three groups with rising average contribution trends as SG (successful groups); the other three with declining trends are designated as FG (failed groups). Then, I perform pairwise Mann-Whitney rank sum tests of difference for the punishment points sent and received between two MPCR types in SG and FG for the first five periods. ${ }^{8}$ My finding: the high-MPCR types receive the same average points in SG and FG $(\mathrm{z}=-1.528)$, but the difference is significant for low-MPCR types $(\mathrm{z}=-1.964$ with $p<0.05$ ). In contrast, there is no difference between the average points sent by low-MPCR types in SG and FG $(\mathrm{z}=-0.655)$, while for high-MPCR types the difference is significant $(\mathrm{z}=-1.964$ with $p<0.05)$. This indicates that, for those groups that successfully achieve cooperation, punishment is imposed mainly by high-MPCR subjects to low-MPCR subjects.

However, higher contribution levels in T3 due to sanctions do not necessarily imply higher group welfare. The sanctioning system itself is costly to maintain, in that punishment reduces the earnings of both the punisher and the recipient. Even when the sanction mechanism is absent, the lower average contribution rates in $\mathrm{T} 2$ do not refer to lower welfare as well. The justification of the statement is that if most of the contributions are from high-productivity subjects in a heterogeneous group, then the high MPCR 0.9 from the group account will compensate for the decrease in the group average contribution level caused by heterogeneity. ${ }^{9}$ Figure 6 shows the average earnings by period in the three treatments.

RESULT 5 The group average earnings of T1, T2 and T3 over 15 periods are similar. Specifically, after the introduction of punishment, the average earnings in T3 are significantly lower than those in $\mathrm{T} 1$ in the first five periods.

8 The reason for selecting the initial five periods instead of the entire 15 periods is that group average contribution levels are close to each other at this time, and just about to diverge into two trends in these periods. If something happens to cause this divergence, it must be the use of the sanction mechanism. Contrast this to what happens in subsequent periods when players respond to sanctioning behavior, punishment is much less frequently used. 9 Imagine there is a group of $\mathrm{T} 1$ and a group of $\mathrm{T} 2$ consisting of four players each. Half of the players in $\mathrm{T} 1$ and the two low-MPCR players in $\mathrm{T} 2$ do not make any contribution into the group account. Since in T2 it is cheaper for high productivity subjects to produce the same amount of output, in order to yield one token from the group account, the two highMPCR subjects in T2 only need to contribute a total of approximately 1.11 tokens. In T1, however, the other two players with MPCR 0.6 have to contribute a total of approximately 1.67 tokens. 


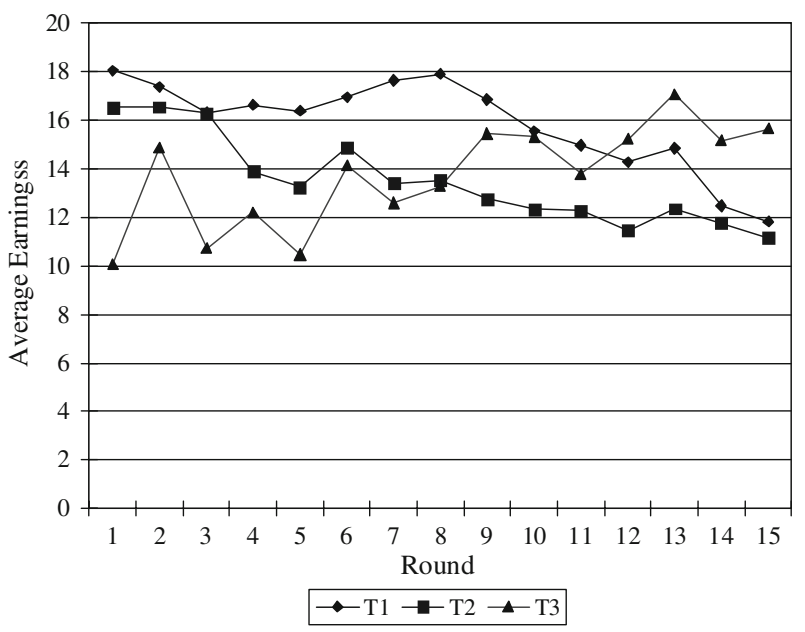

Figure 6 - Average earnings by treatment

In the final five periods, however, mean earnings in $\mathrm{T} 3$ is similar to those in $\mathrm{T} 1$ and significantly higher than those in T2.

SUPPORT FOR RESULT 5:

The mean group earnings over 15 periods is 15.85 for $\mathrm{T} 1$, and 13.47 for $\mathrm{T} 2$ - and the former dominates the latter. This difference is insignificant, however, in either the early periods (periods 1-5) or the final periods (periods 11-15). This also implies that contributions in T2 are indeed mainly made by high-MPCR subjects. The average earnings of T3 in periods $1-5$ is significantly lower than those of $\mathrm{T} 1(\mathrm{z}=-2.17, p<0.05)$, and are similar to those of T2. This implies a substantial decrease in earnings due to sanction costs paid by both punishers and the punished. However, in periods $11-15$, the mean earnings of $\mathrm{T} 3$ is significantly higher than those of $\mathrm{T} 2(\mathrm{z}=2.082$, $p<0.05)$ and the same applies to those of $\mathrm{T} 1$. This result suggests that the sanction system effectively counters the increasing free-rider behavior of a standard public good game in the final periods. The contribution increment marks up the loss of punishment, and results in similar average earnings of $\mathrm{T} 3$ as those of $\mathrm{T} 1$ and $\mathrm{T} 2$ over 15 periods $(\mathrm{z}=-0.32$ and 1.281 , respectively).

\subsection{Individual Analysis}

This section mainly concerns the relationship between sanctions and contributions at the individual level in the presence of heterogeneous productivity. Result 6 aims at finding the determinants of sanction behavior, and Conjecture 1 discusses the effect of sanctions. 


\subsubsection{Conditional sanction assignment}

Fehr and Gächter (2000) observes that agent $i$ assigns more points to $k$ the further $k$ 's contribution falls below the group average contribution. Falk et al. (2005) discovers a positive relationship between the number of monetary punishment points that agent $i$ assigns to agent $k$ and the negative deviation of $k$ 's contribution from that of $i$ 's. Masclet etal. (2003) finds both of the above point-assignment patterns, and also establishes that agents assign more punishments the more recipient's contribution exceeds their own, but fewer points the more the recipient's contribution exceeds the average. This study replicates all of these earlier findings to see whether they also carry over to a group with heterogeneous MPCRs. Besides the above factors, it would be also interesting to see how the MPCR of a punisher and a recipient affect sanction behavior. The regression outcomes of the number of points that agent $i$ assigns to agent $k$ are presented in Result 6 .

RESULT 6 The level of monetary sanction that one agent sends to another is increasing in (i) the negative difference of the contribution of the recipient from the average level, and (ii) the negative difference between the contribution of the recipient and the contribution of the punisher, and (iii) when the recipient has a high MPCR of 0.9. The Conditional Punishment Hypothesis (Hypothesis 5) is thus supported.

SUPPORT FOR RESULT 6:

Table 2 contains the estimates from the following regression model:

$$
\begin{aligned}
P_{i k}^{t}= & \beta_{0}+\beta_{1}\left(\max \left\{0, c_{i}^{t}-c_{k}^{t}\right\}\right)+\beta_{2}\left(\max \left\{0, c_{k}^{t}-c_{i}^{t}\right\}\right) \\
& +\beta_{3}\left(\max \left\{0, \bar{c}^{t}-c_{k}^{t}\right\}\right)+\beta_{4}\left(\max \left\{0, c_{k}^{t}-\bar{c}^{t}\right\}\right) \\
& +\beta_{5} \text { type }_{i}+\beta_{6} t y p e_{k}+\varepsilon_{i k}^{t}
\end{aligned}
$$

type $_{i}=1$ if $i$ has MPCR of 0.9; type $e_{k}=1$ if $i$ has MPCR of 0.9

Because of the large number of zero values for the dependent variable, Tobit and Random Effect Tobit estimations are used for the data. The results are presented in Table $2 .{ }^{10}$

The coefficients of these two models turn out to be rather similar. Both $\beta_{1}$ and $\beta_{3}$ are highly significant, suggesting that agent $i$ assigns more points to agent $k$ the further $k$ 's contribution is below his or her own. On top of this, $i$ sends even more points if $k$ contributes below the group average level. These two findings are consistent with the current literature on punishment (Fehr and Gächter (2000); Masclet et al. (2003); Falk et al. (2005); Noussair and Tucker (2005)). Given all of the contribution information in a period, sanction behavior also seems to be sensitive to the type of agent. The positive and significant coefficient $\beta_{6}$ suggests that ceteris paribus, an agent with

10 The standard errors of the Tobit model are robust to within group correlation. The individual effect in the Random Effect Tobit model is agent $i$ (the punisher). 
TABLE 2 - DETERMINANTS OF SANCTIONING BEHAVIOR

\begin{tabular}{|c|c|c|}
\hline & $\begin{array}{l}\text { Tobit model (with } \\
\text { robust std. errors) }\end{array}$ & $\begin{array}{l}\text { Random Effect } \\
\text { Tobit model (indi- } \\
\text { vidual effect: } i \text { ) }\end{array}$ \\
\hline \multicolumn{3}{|l|}{ Dependent variable: $P_{i k}^{t}$} \\
\hline$\beta_{0}$ Constant & $\begin{array}{l}-5.326^{* * *} \\
(1.975)\end{array}$ & $\begin{array}{l}-6.595^{* * *} \\
(0.750)\end{array}$ \\
\hline $\begin{array}{l}\beta_{1} \text { Negative deviation from } i \text { 's own } \\
\text { contribution }\end{array}$ & $0.546^{* *}$ & $0.542 * * *$ \\
\hline$\left(\max \left\{0, c_{i}-c_{k}\right\}\right)$ & $(0.259)$ & $(0.121)$ \\
\hline $\begin{array}{l}\beta_{2} \text { Positive deviation from } i \text { 's own } \\
\text { contribution }\end{array}$ & 0.078 & 0.170 \\
\hline$\left(\max \left\{0, c_{k}-c_{i}\right\}\right)$ & $(0.223)$ & $(0.141)$ \\
\hline$\beta_{3}$ Negative deviation from average & $0.799 * *$ & $0.848 * * *$ \\
\hline$\left(\max \left\{0, \bar{c}-c_{k}\right\}\right)$ & $(0.352)$ & $(0.199)$ \\
\hline$\beta_{4}$ Positive deviation from average & -0.162 & -0.296 \\
\hline$\left(\max \left\{0, c_{k}-\bar{c}\right\}\right)$ & $(0.242)$ & $(0.241)$ \\
\hline \multirow[t]{2}{*}{$\beta_{5}$ type $_{i}(1$ when $i$ has high MPCR) } & -0.497 & -0.088 \\
\hline & $(1.096)$ & $(0.738)$ \\
\hline \multirow[t]{2}{*}{$\beta_{6}$ type $_{k}(1$ when $k$ has high MPCR) } & $0.787^{*}$ & $1.238 * * *$ \\
\hline & $(0.475)$ & $(0.409)$ \\
\hline Log-likelihood & -744.01 & -737.07 \\
\hline Observations & 1080 & 1080 \\
\hline
\end{tabular}

Note: The number of observations is calculated as: 3 (messages) $\times 4$ (players) $\times 15$ (periods) $\times 6$ (groups) $=1080 . * * * 1 \%$ Significance level, $* * 5 \%$ significance level, $* 10 \%$ significance level. Standard errors in parentheses

a high productivity level will receive more points than one with a low productivity level. However, the type of the punisher, $\beta_{5}$, is not significant, meaning there is no distinct difference in sanctioning behavior between high- and lowMPCR types.

Although the estimated $\beta_{4}$ is not significant, the so-called "spiteful behavior" reported by Falk etal. (2005) and Masclet etal. (2003) is unlikely to be the correct explanation in this experiment. Instead, this result may be explained by the asymmetric structure of this game: it is plausible for every member in a group to expect high-MPCR subjects to make more contribution than the low-MPCR subjects would makes, since it would be cheaper. The results in the previous section indicate that the contributions of highMPCR types are significantly higher than those of the low-MPCR types, which implies that it is much more difficult to trigger any possible spiteful preferences in this case than it would be if agents in a group were symmetric. That may be the reason why a higher positive deviation player $k$ 's contribution from player $i$ 's does not lead to higher punishment from player $i$. 


\subsubsection{Sanction effect}

One result in Fehr and Gächter (2000) is that agents receiving punishment in time period $t$ usually increase their contributions in the subsequent period. This study replicates the analysis to see whether it still holds.

Conjecture 1: ${ }^{11}$ An individual increases his or her contribution level in the subsequent period: (i) the more points he or she receives in period t, and (ii) the further his or her contribution is away from the group average level and (iii) when he or she has an MPCR of 0.9 AND his or her contribution is below the group average level.

\section{SUPPORT FOR CONJECTURE 1:}

An estimation of regression contribution change within two time periods on the factors discussed above may be expressed as formula (5). Similar to the Conditional Sanction discussed in the previous section, a dummy variable is also added to the regression representing the MPCR of the recipient.

$$
\begin{gathered}
c_{i}^{t+1}-c_{i}^{t}=\beta_{0}+\beta_{1}\left(\sum_{k}^{P_{k i}}\right)+\beta_{2}\left(c_{i}^{t}-\bar{c}^{t}\right)+\beta_{3} \text { type } i+\varepsilon_{i}^{t} \\
\text { type }_{i}=1 \quad \text { if } i \text { has MPCR of } 0.9
\end{gathered}
$$

$\beta_{1}$ calibrates the effect of the total number of points agent $i$ receives on his or her change in contribution from one period to the next; $\beta_{2}$ is the effect of the difference between individual i's contribution and his or her group average contribution level in period $t ; \beta_{3}$ is the MPCR type of the recipient. The model is estimated separately for players who contributed more than the group average and less than the group average in time period $t .{ }^{12}$

A pooled OLS model and a Random Effect model are estimated, and the results are highly similar. The coefficients of $\beta_{2}$ in Tables 3 and 4 show a significantly negative relation between the deviation from the average and the subsequent change in the contribution level, which is again consistent with the current findings in studies such as Masclet et al. (2003): Agents have the tendency to make their contributions stay close to the group average level. Furthermore, the coefficient of $\beta_{1}$ in Table 3 suggests that there is a positive relationship between the points received in period $t$ and the change of contribution when one's contribution is lower than group average level. What

11 The reason for designating the relationship as a conjecture is the same as that of Masclet et al. (2003): we cannot be certain that the points themselves (rather than other possible variables correlated with the number of points received) cause the increase in contribution. 12 A Chow test rejects the null hypothesis that there are no behavioral structural differences between players who contribute more than group average and those less than group average. (with $p<0.01$ ). 
TABLE 3 - DETERMINANTS OF CHANGES IN CONTRIBUTION:

\section{LOW CONTRIBUTORS}

\begin{tabular}{|c|c|c|}
\hline & OLS & $\mathrm{RE}$ \\
\hline \multicolumn{3}{|c|}{ Dependent variable: $c_{j}^{t+1}-c_{j}^{t} \quad$ for $\left(c_{j}^{t}-\bar{c}^{t}<0\right)$} \\
\hline$\beta_{0}$ Constant & $\begin{array}{l}-0.705^{* *} \\
(0.292)\end{array}$ & $\begin{array}{l}-0.567 \\
(0.391)\end{array}$ \\
\hline$\beta_{1}$ Points received in & $0.190^{* * *}$ & $0.221^{* * *}$ \\
\hline period $t$ & $(0.061)$ & $(0.068)$ \\
\hline$\beta_{2}$ Deviation from the & $-0.527 * * *$ & $-0.511^{* * *}$ \\
\hline average & $(0.138)$ & $(0.134)$ \\
\hline$\beta_{3}$ type $_{i}(1$ when $i$ has & $0.895^{* * *}$ & $0.809^{*}$ \\
\hline high MPCR) & $(0.317)$ & $(0.478)$ \\
\hline $\mathrm{R}^{2}$ & 0.221 & 0.235 \\
\hline Observations & 161 & 161 \\
\hline
\end{tabular}

Note: The individual effect in the Random Effect model is player $i .{ }^{* * *} 1 \%$ Significance level, $* * 5 \%$ significance level, $* 10 \%$ significance level. Standard errors in parentheses

TABLE 4 - DETERMINANTS OF CHANGES IN CONTRIBUTION: HIGH CONTRIBUTORS

\begin{tabular}{|c|c|c|}
\hline & OLS & RE \\
\hline \multicolumn{3}{|c|}{ Dependent variable: $c_{i}^{t+1}-c_{i}^{t}$ for $\left(c_{i}^{t}-\bar{c}^{t}>0\right)$} \\
\hline$\beta_{0}$ Constant & $\begin{array}{l}-0.272 \\
(0.354)\end{array}$ & $\begin{array}{l}-0.272 \\
(0.391)\end{array}$ \\
\hline$\beta_{1}$ Points received in & $0.266^{* *}$ & $0.266^{* *}$ \\
\hline period $t$ & $(0.110)$ & $(0.110)$ \\
\hline$\beta_{2}$ Deviation from & $-0.731^{* * *}$ & $-0.731 * * *$ \\
\hline the average & $(0.134)$ & $(0.134)$ \\
\hline$\beta_{3}$ type $_{i}(1$ when $i$ has & 0.362 & 0.362 \\
\hline high MPCR) & $(0.402)$ & $(0.402)$ \\
\hline $\mathrm{R}^{2}$ & 0.178 & 0.194 \\
\hline Observations & 151 & 151 \\
\hline
\end{tabular}

Note: The individual effect in the Random Effect model is player $i . * * * 1 \%$ Significance level, $* * 5 \%$ significance level, * $10 \%$ significance level. Standard errors in parentheses

is different here from Masclet etal. (2003) is that this result carries over to those subjects with contributions higher than the group average level. A possible explanation may again be found in the asymmetric structure of the game, in that high-MPCR types are expected to contribute more.

The sign and significance of $\beta_{3}$ in Table 3 indicate that high-MPCR types are more sensitive to punishment - but only when their contributions are below the mean level. Whereas these players will dramatically increase their 
contribution when they receive a punishment point when their contributions are below group average, the behavioral differences between the two types are no longer significant once the contributions exceed group average. This may be due to the lacking data available to low-MPCR types on subjects that have contributions higher than group average. This also naturally leads to another explanation: that it is relatively unusual for low-MPCR types to contribute more than the group average - although when they do, it may reflect an altruistic character that is difficult to alter by punishment. As a result, punishments to an altruistic low-MPCR agent may turn out to be a stimulant for that agent to contribute even more in the next period.

\section{CONCLUSION}

This study examines cooperation and sanction behavior through a four-person linear public good game in which agents are asymmetric in productivity. The data analysis reveals the following conclusions. Without a sanction mechanism, the mean contribution level of a group with heterogeneous productivity is lower than that of a homogeneous group with the same average MPCR. This is caused by severe free riding among low-productivity subjects, together with insufficient contributions by high-productivity subjects. The imposition of sanction significantly enhances cooperation, but because of the cost of enforcing this system, the earnings under three treatments are similar. In groups in which cooperation is successfully achieved, high-productivity subjects punish low-productivity subjects actively. Conditional on individual contribution levels, however, high-MPCR types receive more punishment, and behave more responsively by making higher contributions in the next period.

When the productivity level of every participant is made public, the presumption that high-productivity subjects should carry more responsibility regarding fostering cooperation seems to become common knowledge, or a social norm, in this game. ${ }^{13}$ As explained in Fehr and Fischbacher (2004), this social norm stems from the fact that the behavior of productive agents generates greater side effects than does the behavior of their less productive counterparts. The results mirror the reality in which elites in a society are under higher pressure, since their choices deeply impact a society. The efficiency and robustness of this social norm needs to be further investigated, however, since punishment neither increases welfare nor guarantees a successful cooperation in this asymmetric game. Further research may give agents

13 This can be supported from the result that the behavior of high-MPCR subjects influences the cooperation outcome to a large extent. Under sanction institution, it will be those who suffered higher punishment given the same amount of contribution; in successful groups, it will be those who impose severe punishment to defectors; whereas in failed groups, it will be those who do not use sanction system. 
the power to vote for institutions, in order to investigate whether the "participation constraint" of the sanction mechanism is satisfied, and who would prefer to live in a society with this norm, given the choice. If a public choice process of a social institution is driven by evolutionary forces, this will eventually drive out institutions with costly sanctions.

\section{ACKNOWLEDGEMENTS}

I am grateful to Professor Charles Noussair, Jan Potters, Urs Fischbacher, the anonymous referee, and participants at the NAKE research day 2007 in Utrecht, the Netherlands, for their valuable comments and suggestions. I would also like to thank CentER Lab for financial support. Views, omissions and errors are, of course, my own. Experiment instructions and raw data are available upon request.

Open Access This article is distributed under the terms of the Creative Commons Attribution Noncommercial License which permits any noncommercial use, distribution, and reproduction in any medium, provided the original author(s) and source are credited.

\section{REFERENCES}

Anderson, L., J. Mellor and J. Milyo (2004), Inequality, Group Cohesion, and Public Good Provision: An Experimental Analysis, University of Missouri Economics Working Paper Series.

Andreoni, J. (1988), 'Why Free Ride? Strategies and Learning in Public Goods Experiments,' Journal of Public Economics, 37, pp. 291-304.

Bagnoli, M. and M. Mckee (1991), 'Voluntary Contribution Games: Efficient Private Provision of Public Goods,' Economic Inquiry, 29(2), pp. 351-366.

Bochet, O., T. Page and L. Putterman (2006), 'Communication and Punishment in Voluntary Contribution Experiments,' Journal of Economic Behavior and Organization, 60, pp. 11-26.

Bowles, S., J. Carpenter, and H. Gintis (2001), 'Mutual Monitoring in Teams: Theory and Evidence on the Importance of Residual Claimancy and Reciprocity,' SFI Working Paper.

Buckley, E. and R. Croson (2006), 'Income and Wealth Heterogeneity in the Voluntary Provision of Linear Public Goods,' Journal of Public Economics, 90(5), pp. 935-955.

Carpenter, J. (2007), 'Punishing Free-riders: How Group Size Affects Mutual Monitoring and the Provision of Public Goods, Games and Economic Behavior, 60, pp. 31-51.

Carpenter, J., A. Daniere, and L. Takahashi (2004), 'Cooperation, Trust, and Social Capital in Southeast Asian Urban Slums,' Journal of Economic Behavior \& Organization, 55(4), pp. 533-551.

Chan, K., S. Mestelman, R. Moir and R. Muller (1996), 'The Voluntary Provision of Public Goods Under Varying Income Distributions,' Canadian Journal of Economics, 29(1), pp. 54-69.

Chan, K., S. Mestelman, R. Moir and R. Muller (1999), 'Heterogeneity and the Voluntary Provision of Public Goods,' Experimental Economics, 2, pp. 5-30. 
Cherry, T., S. Kroll and J. Shogren (2005), 'The Impact of Endowment Heterogeneity and Origin on Public Good Contributions: Evidence from the Lab,' Journal of Economic Behavior \& Organization, 57(3), pp. 357-365.

Denant-Boemont, L., D. Masclet and C.Noussair (2007), 'Punishment, Counter-Punishment and Sanction Enforcement in a Social Dilemma Experiment,' Economic Theory, 33(1), pp. 145-167.

Falk, A., E. Fehr and U. Fischbacher (2005), 'Driving Forces Behind Informal Sanctions,' Econometrica, 73(6), pp. 2017-2030.

Fehr, E. and S. Gächter (2000), 'Cooperation and Punishment in Public Goods Experiments,' American Economic Review, 90(4), pp. 980-994.

Fehr, E. and S. Gächter (2002), 'Altruistic Punishment in Humans,' Nature, 415, pp. 137-140.

Fehr, E. and U. Fischbacher (2004), 'Social Norm and Human Cooperation,' Trends in Cognitive Sciences, 8(4), pp. 185-190.

Fischbacher, U. (2007), 'Z-Tree - Zurich Toolbox for Readymade Economic Experiments,' Experimental Economics, 10(2), pp. 171-178.

Fisher, J., R. Isaac, J. Schatzberg and J. Walker (1995), 'Heterogeneous Demand for Public Goods: Behavior in the Voluntary Contributions Mechanism,' Public Choice, 85, pp. 249-266.

Isaac, R., K. McCue and C. Plott (1985), 'Public Goods Provision in an Experimental Environment,' Journal of Public Economics, 26, pp. 51-74.

Isaac, M. and J. Walker (1988), 'Group Size Effects in Public Goods Provision: The Voluntary Contribution Mechanism,' Quarterly Journal of Economics, 103(1), pp. 179-199.

Kim, O. and M. Walker (1984), 'The Free Rider Problem: Experimental Evidence,' Public Choice, (1), pp. 3-24.

Ledyard, J. (1995), 'Public Goods: A Survey of Experimental Research,' in: J. Kagel and A. Roth (eds.) The Handbook of Experimental Economics, Princeton University Press.

Marwell, G. and R. Ames (1979), 'Experiments on the Provision of Public Goods. I. Resources, Interest, Group Size, and the Free-Rider Problem,' The American Journal of Sociology, 84(6), pp. 1335-1360.

Marwell, G. and R.Ames (1980), 'Experiments on the Provision of Public Goods. II. Provision Points, Stakes, Experience, and the Free-Rider Problem,' The American Journal of Sociology, 85(4), pp. 926-937.

Masclet, D., C. Noussair, S. Tucker and M. Villeval (2003), 'Monetary and Non-monetary Punishment in the Voluntary Contributions Mechanism,' American Economic Review, 93(1), pp. 366-380.

Nikiforakis, N. (2008), 'Punishment and Counter-Punishment in Public Good Games: Can We Really Govern Ourselves?' Journal of Public Economics, 92(1-2), pp. 91-112.

Nikiforakis, N., H. Normann and B. Wallace (2007), Asymmetric Enforcement of Cooperation in a Social Dilemma, University of Melbourne Economics Working Paper No. 982.

Noussair, C. and S. Tucker (2005), 'Combining Monetary and Social Sanctions to Promote Cooperation,' Economic Inquiry, 43(3), pp. 649-660.

Olson, M. (1971), The Logic of Collective Action: Public Goods and the Theory of Groups, Harvard University Press, Cambridge, MA.

Ostrom, E., J. Walker and R. Gardner (1992), 'Covenant with and without a Sword: Selfgovernance is Possible,' American Political Science Review, 86(2), pp. 404-417.

Oxoby, R. and J. Spraggon (2006), A Clear and Present Minority: Heterogeneity in the Source of Endowments and Provision of Public Goods, University of Calgary Economics Working paper. 
Palfrey, T. and J. Prisbrey (1997), 'Anomalous Behavior in Public Goods Experiment: How Much and Why,' The American Economic Review, 87(5), pp. 829-846.

Potters, J., M. Sefton and L. Vesterlund (2007), 'Leading-By-Example and Signaling in Voluntary Contribution Games: An Experimental Study,' Economics Theory, 33(1), pp. 169-182.

Sefton, M., R. Shupp and J. Walker (2007), 'The Effect of Rewards and Sanctions in Provision of Public Goods,' Economic Inquiry, 45(4), pp. 671-690.

Weimann, J. (1994), 'Individual Behavior in a Free Riding Experiment,' Journal of Public Economics, 54(2), pp. 185-200.

Yamagishi, T. (1986), 'The Provision of a Sanctioning System as a Public Good,' Journal of Personality and Social Psychology, 51(1), pp. 110-116. 